\title{
Symmetrical peripheral gangrene: a rare presentation of antiphospholipid syndrome
}

\author{
Abdul Hai • Mohammed Aslam • Tarique H. Ashraf
}

Received: 21 July 2011/Accepted: 13 October 2011/Published online: 1 November 2011

(C) SIMI 2011

A 25-year-old woman presented with complaints of dark discolouration of the hands, feet and the tip of the nose 1 week after normal delivery of a preterm baby (28 weeks) in April 2009. The onset was subacute and the discolouration progressed to the wrists and just above the ankles in a bilaterally symmetrical fashion. There was a history of fever from the onset of symptoms. There was no prior history of diabetes or cardiovascular illness. The baby had to be kept in the neonatal intensive care unit for 2 weeks hospitalization, as he was premature, and suffering from acute respiratory distress.

On examination, the vital signs were: pulse 94 beats per minute and blood pressure of $118 / 72 \mathrm{~mm} / \mathrm{Hg}$, respirations $18 \mathrm{breaths} / \mathrm{min}$. She had superficial pregangrene of the tip of the nose (Fig. 1), hands and feet extending to the distal leg. Superficial ulcerations were absent (Fig. 2). The skin of pregangrenous area was dry. The patient could move her hands and feet, but there was partial loss of sensation in the area of superficial pregangrene. She had moderate pallor,

The article has not been presented to any meeting or society.

\section{A. Hai}

Department of Surgery, Hamdard Institute of Medical Sciences and Research, Jamia Hamdard University, New Delhi, India

\section{A. Hai $(\square)$}

Aleem Manzil, Sir Syed Nagar, Civil Line, Aligarh 202002, Uttar Pradesh, India

e-mail: abdulhaiqadar@yahoomail.com

\section{Aslam}

Department of Medicine, Hamdard Institute of Medical Sciences and Research, Jamia Hamdard University, New Delhi, India

\section{T. H. Ashraf}

Department of Surgery, Chattarpati Sahuji Maharaj Medical University, Lucknow, India but no cyanosis. Examinations of the chest and abdomen were normal. The hemoglobin was $9.5 \mathrm{gm} \%$, blood urea $22 \mathrm{mg} \%$ and serum creatinine $1 \mathrm{mg} \%$. Her platelet count, prothrombin time and activated partial thromboplastin time were normal. A blood culture was negative. The anticardiolipin antibody (aCL) test was positive however a Lupus anticoagulant (LCA) test was not done. Protein C, protein S and antithrombin III levels were normal. Antinuclear antibody test and antibodies to double stranded DNA (ds-DNA) for systemic lupus erythematosus were negative. The chest X-ray study as well as a urinalysis was normal. The ultrasonography of the pelvis showed a mildly enlarged uterus without any fluid collection in the pelvis. The aCL test was still positive after 6 weeks.

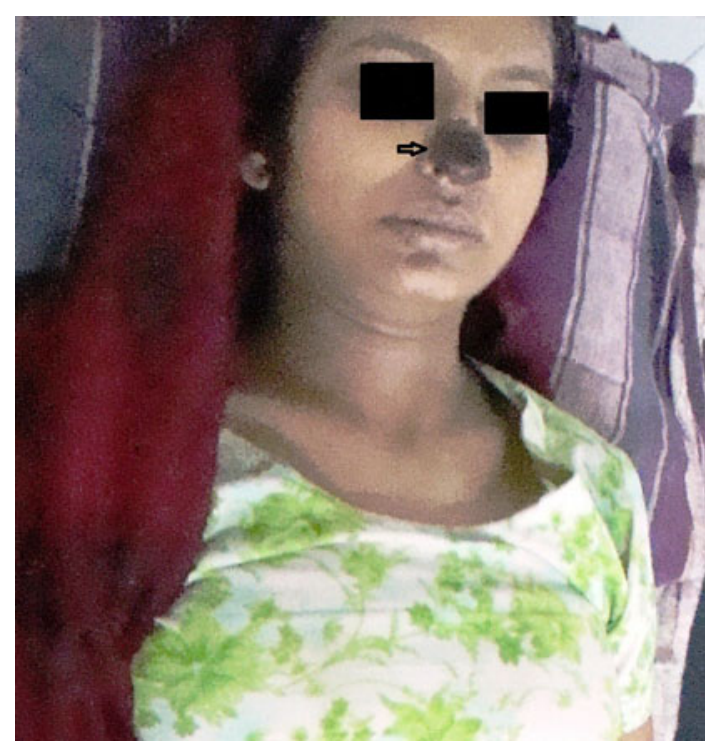

Fig. 1 The arrow shows superficial gangrene of the tip of the nose in a young female 
Fig. 2 Arrows show superficial gangrene of the skin of the hands and feet in the same patient

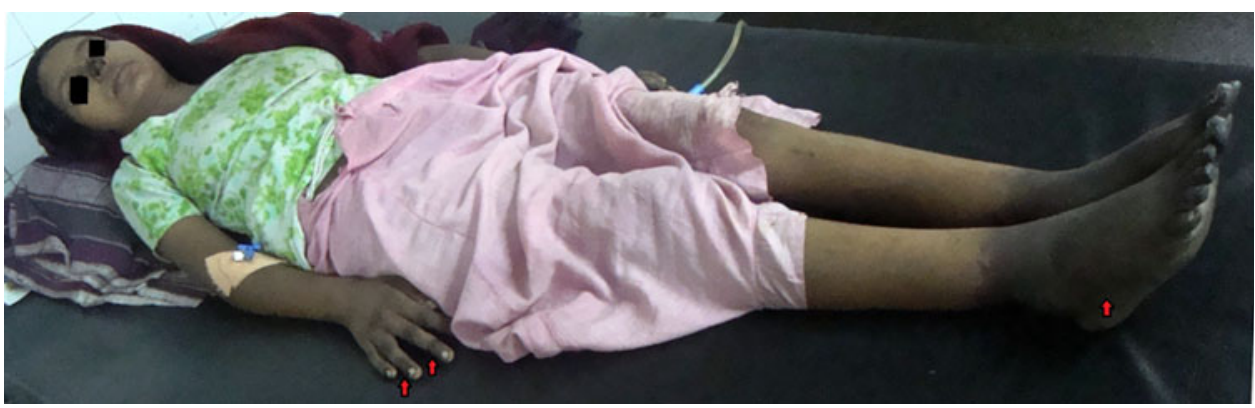

She was managed conservatively and started on anticoagulant therapy. Intravenous heparin was started. Oral Warfarin (5 mg twice a day) was started on the 4th day and heparin withdrawn slowly. The pregangrenous areas regressed slowly in 2 weeks time and she regained the loss of touch sensation. She did not require any sort of surgical intervention.

Antiphospholipid syndrome (APS) is a clinicopathological syndrome in which a clinical spectrum is found associated with a persistently positive test for antiphospholipid antibodies [1]. The antiphospholipid antibodies are immunoglobulin $\mathrm{G}$ (IgG) types and include two types of antibodies; aCL and LCA antibodies. They are directed against proteins ( $\beta 2$-glycoproteins and prothrombins), which bind to phospholipids found in the cell membranes. In vivo, they predispose to clotting by interfering with the antithrombotic role of phospholipids. This sequence of events leads to recurrent thrombosis in the vessels, both arteries and veins. The syndrome has a varied presentation resulting from recurrent thrombosis at different sites. Deep venous thrombosis of the leg veins is the most common manifestation. Venous thrombosis at unusual sites like the inferior vena cava, axillary, splenic and renal veins may also be present. Arterial thrombosis is uncommon, manifesting as ischemia and infarction of various organs like brain, skin, heart and mesentery [2]. The other manifestations of APS include livedo reticularis, catastrophic APS, transverse myelitis, skin necrosis and chorea [1]. Superficial pregangrene of the tip of the nose and hands and feet in a bilaterally symmetrical fashion as in our patient, is a very rare presentation [3, 4].

In women, APS also manifests as infertility and pregnancy complications such as recurrent first trimester abortions, severe preeclampsia, prematurity and still births. In our patient apart from skin manifestations, prematurity was the presenting pregnancy complication. Fetal death beyond 20 weeks' gestation may also be due to APS, the rate being upto $90 \%$ in untreated patients. APS is now most frequently diagnosed in women with adverse outcomes of pregnancy [1]. Anticoagulant therapy including heparin and aspirin can reduce the rate of fetal loss to $25 \%$.

APS is of two types. Primary APS is described when it occurs in the absence of other diseases. Secondary APS is seen in conjunction with other autoimmune diseases like systemic lupus erythematosus (SLE), rheumatoid arthritis, systemic sclerosis, Behcet's syndrome, temporal arteritis and Sjögren's syndrome [1]. The diagnostic criteria for APS include at least one clinical manifestation in the form of an adverse pregnancy outcome, or other disease manifestations along with a positive LCA/aCL test. The antibody test is considered positive if either of the two antibody tests is positive. An LCA test is done using a coagulation test based on dilute Russell's viper venom time, however aCL is detected using an enzyme-linked immunosorbent assay (ELISA) immunological test, which screens for the presence of these antibodies [5].Our patient met the diagnostic criteria as she had one clinical manifestation in the form of an adverse pregnancy outcome of prematurity along with a positive aCL test. There was no previous history of autoimmune diseases, so she was suffering from primary APS. We excluded the diagnosis of lupus in our patient as a ds-DNA was negative, and the involvement was peripheral.

Treatment of the acute event of thrombosis in patients with APS is anticoagulation starting with intravenous heparin and then subsequently, oral anticoagulation [4]. As patients with APS have higher risk of recurrence of thrombotic events, they should be given long term oral anticoagulation for at least 6 months after the first episode. If recurrent thrombosis occurs, then low dose anticoagulation should be given lifelong. Low molecular weight heparins can also be used for the same purpose. The treatment of pregnant women who have the antiphospholipid antibody syndrome can result in a much higher success rate for the pregnancy. In pregnant women who are known to be suffering from APS but do not have thrombotic events, low dose aspirin is the general recommendation.

\section{Conflict of interest None.}

\section{References}

1. Craig JIO, McClelland DBL, Watson HG (2010) Blood disease. In: Colledge NR, Walker BR, Ralston SH (eds) Davidson's principles and practice of medicine, 21st edn. Churchill Livingstone, Edinburgh, pp 985-1051 
2. Marques MA, Murad FF, Ristow AV, Silveira PR, Pinto JE, Gress MH, Massière B, Cury JM, Vescovi A (2010) Acute carotid occlusion and stroke due to antiphospholipid antibody syndrome: case report and literature review. Int Angiol 29:380-384

3. Grob JJ, Bonerandi JJ (1989) Thrombotic skin disease as a marker of the anticardiolipin syndrome: Livedo vasculitis and distal gangrene associated with abnormal serum antiphospholipid activity. J Am Acad Dermatol 20:1063-1069

4. Bapat SS, Pulikot AM, Naik P, Chinchankar N (2001) Antiphospholipid antibody syndrome. Indian pediatr 38:1413-1416

5. Hughes GR (1983) Thrombosis, abortion, cerebral dis-ease, and the lupus anticoagulant. Br Med J 287:1088-1089 